\title{
Design \& Development of a Trans Tibial Socket Stabilized by Alternating Areas of Tissue Compression and Release - A Case Study
}

\author{
Prachi Prava Pattnaik ${ }^{1}$, Jonathan $\mathrm{T}^{2}$ \\ ${ }^{1}$ Lecturer, Dept. of Prosthetics \& Orthotics, Christian Medical College, Vellore \\ ${ }^{2}$ Intern, Dept. of Prosthetics \& Orthotics, Christian Medical College, Vellore
}

Corresponding Author: Prachi Prava Pattnaik

\begin{abstract}
The socket is the most important aspect of the artificial limb, constituting the critical interface between the amputee's stump and prosthesis. The design and fitting of the socket is also the most difficult procedure due to the uniqueness of each amputee's stump. An uncomfortable socket fit is the most common complaint from lower limb amputees with surveys revealing that amputees believe comfort are the most important aspects of the prosthesis and over half of all wearers are in moderate to severe pain for most of the time whilst wearing the prosthesis. Kristinsson argued that a transtibial socket can be designed to transfer loads primarily to limited areas of the limb such as the patella tendon and the medial flare, which in most cases found both ineffective and uncomfortable. There were inconsistencies in producing satisfactory PTB sockets because of inadequate training of Prosthetist in the PTB technique. However, the TSB silicon liner socket has problems such as causing excessive perspiration, heating and odor etc. Therefore, a new socket is designed following the principle of alternative pressure and release to overcome the disadvantages and to check the socket with regard to stability, comfort and satisfaction.

Method: A single case study of a person 37-year-old, with transtibial amputation population took part in this study and was selected according to the inclusion criteria. The participant was provided patient information sheet and after taking the informed consent, the assessment and fabrication of the new socket were being proceeded, taking the cast on the first day. On the third day the newly designed socket along with prosthesis was provided with an adaptation period of 7 days. After 7 days the patient was called to check the stability with standing, comfort and satisfaction with a prosthetic socket comfort score.

Results and Discussion: The present socket is well suitable for transtibial patient in weight bearing position. It fits well to the contour of the adult patient. The socket was adjusted manually during rectification phase providing respective pressure in areas required.

Conclusion: The developed socket had a great effect on gait pattern of transtibial amputee. This socket provides adjustment for pressure, anterior, posterior, medial and lateral of the stump. It also creates surface for the placement of bony prominences. As it is a complex casting procedure, proper care should be taken to fabricate the casting of socket with minimal error. Further, innovative inventions will be required to refine more products and extensive study has to be carried out on the existing mode.
\end{abstract}

Keywords: transtibial amputation, transtibial socket, tissue compression and release

\section{INTRODUCTION}

Amputation of the lower extremities continues to be a major problem due to vascular-related diseases e.g. diabetes. It occurs prevalently in countries affected by landmines, high incidents of motor vehicle accidents and natural disasters like earthquakes. A key component of amputee 
rehabilitation is the engineering of devices suited to individuals in order to recover physical capabilities. A prosthesis or artificial limb is one such device that aims to substitute the loss of a limb with cosmetic and functional desirability for the amputee that consist of an assembly of several components such as socket, shank, ankle and foot. The socket can be considered as the most important aspect of the artificial limb, which constitutes the critical interface between the amputee's stump and prosthesis. The design and fitting of the socket is also the most difficult procedure due to the uniqueness of each amputee's stump. An uncomfortable socket fit is the most common complaint from lower limb amputees with surveys revealing that amputees believe comfort are the most important aspects of the prosthesis and over half of all wearers are in moderate to severe pain for most of the time whilst wearing the prosthesis ${ }^{[1]}$. Socket design has evolved from basic conical designs to total-surface bearing sockets. Differing opinions still exist regarding the biomechanical characteristics that a prosthetic socket should possess.

The patellar-tendon-bearing (PTB) socket, which originated in the 1950s, used the design criterion that pressure should vary according to the pain threshold of different tissues in the residual limb ${ }^{[2-3]}$. Further it was noted that, since soft tissues were displaced during loading, a socket that simply made equal contact with the surface area of the residual limb might cause more pressure over bony anatomy and less pressure over soft tissues, because force flow distributed itself proportional to the stiffness of the available paths. These bony areas may not be able to tolerate these high stresses.

However, there were inconsistencies in producing satisfactory PTB sockets. The difficulties were largely because of inadequate training of prosthetist in the PTB technique.

Afterwards, the silicone suction suspension (3S) sockets were introduced to the market ${ }^{[4-5]}$. These systems were characterized by improved techniques of suspension, total surface bearing (TSB), and hydrostatic loading. Kristinsson ${ }^{[6]}$ argued that a transtibial socket can be designed to transfer loads primarily to limited areas of the limb such as the patella tendon and the medial flare, which in most cases found both ineffective and uncomfortable. The most effective socket, in his view was one that relied on the hydrostatic principle for load transfer. The hydrostatic principle for load transfer is possible when the volume of the soft tissues in a residual limb is contained in the same volume in a socket so that no fluid is lost or tissue is displaced from this volume, hence achieving a closed system $^{[7]}$.

However, the TSB silicon liner socket has problems such as causing excessive perspiration, heating and odor etc. Therefore, a new socket is designed following the principle of alternative pressure and release to overcome the disadvantages and to check the socket with regard to stability, comfort and satisfaction.

\section{PROTOCOL}

A single case study of a person 37year-old, with transtibial amputation population took part in this study and was selected according to the inclusion criteria. Initially the subject was evaluated having 2 years- post amputation, ideal stump with good hand muscle power. The exclusion criteria were allergic to skin, Short stump, Hand muscle weakness, Heart problem, Hypertension and Vascular disease. The subject was a previous user. So a worn out period of 15 days had been provided. The participant was provided patient information sheet and after taking the informed consent, the assessment and fabrication of the new socket were being proceeded, taking the cast on the first day. On the third day the newly designed socket along with prosthesis was provided with an adaptation period of 7 days. After 7 days the patient was called to check the stability with standing, comfort 
Prachi Prava Pattnaik et.al. Design \& development of a trans tibial socket stabilized by alternating areas of tissue compression and release - a case study.

and satisfaction with a prosthetic socket comfort score.

\section{NEW CONCEPT DESIGN}

The theory of the CSR socket had been applied to all amputation levels and was not applied for the level of transtibial amputation. So this theory had been applied according to the Kristinsson principle.

The CRS socket technology improved sockets for persons with TR, TH, and transfemoral (TF) amputations creates longitudinal depressions in the socket walls with open release areas between the depressions that had received the displaced tissue. When the depressions and release areas are correctly located, they reduce the motion of the underlying bony structures with respect to both the socket and rest to the prosthesis. One can define the depressions and release and can conclude that the cast-taking can only be changed by radically changing the way casts.

Release areas between depressions are opened to accommodate displaced tissue. Without these openings, the CRS socket will not function as intended. Often, the release areas of compression are the struts, and the regions between struts are left open. A frame with openings can be modified by the prosthetist by adding a thin membrane fully surrounding the limb and allowing the membrane with underlying tissue to enter the release openings. If during the cast-taking, the technician pushes inward towards the bone, a depression will be created in the resulting cast. When the depressed area is parallel to the length of the underlying bone, it appears as a channel or longitudinal depression. If one pushes a substantial area inward while holding the limb of the amputee, this will result in displace of the tissue in other areas outward to form bulges. When the cast is taken, the stretched plaster wrap over these bulges will apply some inward force. For a CRS socket to perform correctly, these areas should have little or no inward force where the tissues bulge. Finally, the remaining force will be removed between the longitudinal depressions, and the areas between them are defined as release areas.

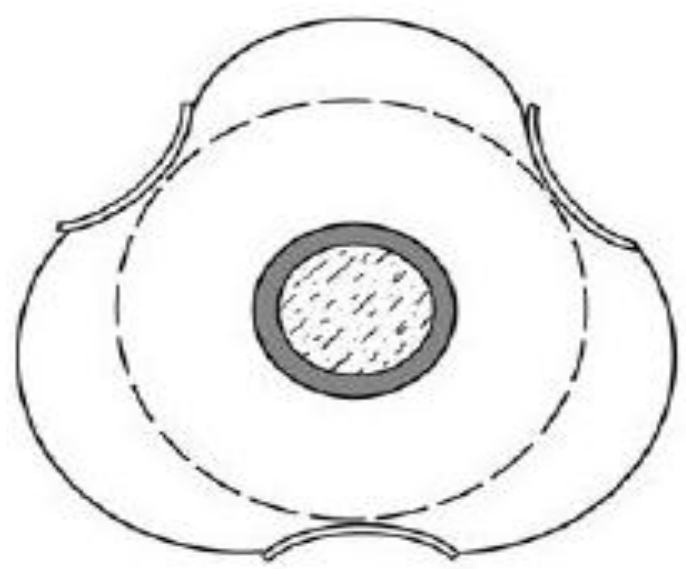

Fig.1 Cross sections showing three designs for tissue compression by incorporating longitudinal depressions into socket

\section{Fabrication procedure: -}

CAST TAKING:

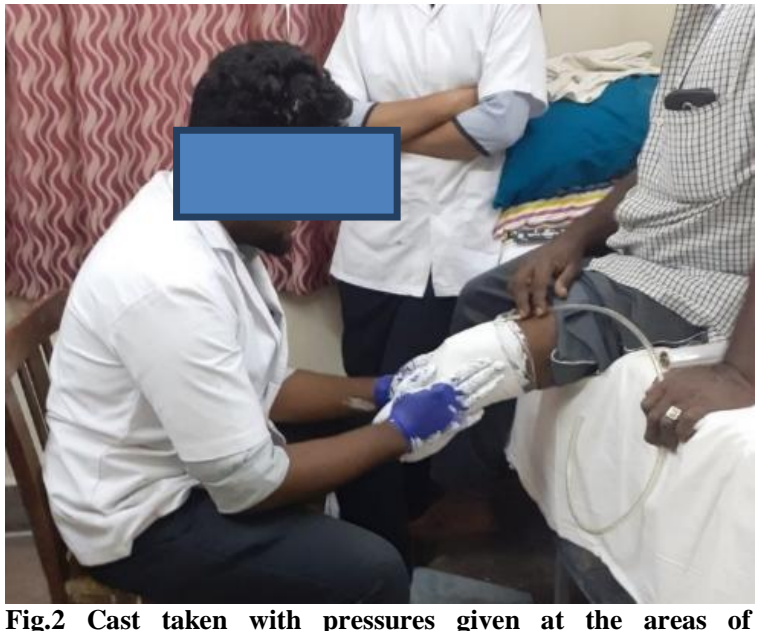

Fig.2 Cast taken with pressures given at the areas of compression

\section{MODIFIED MOLD:}

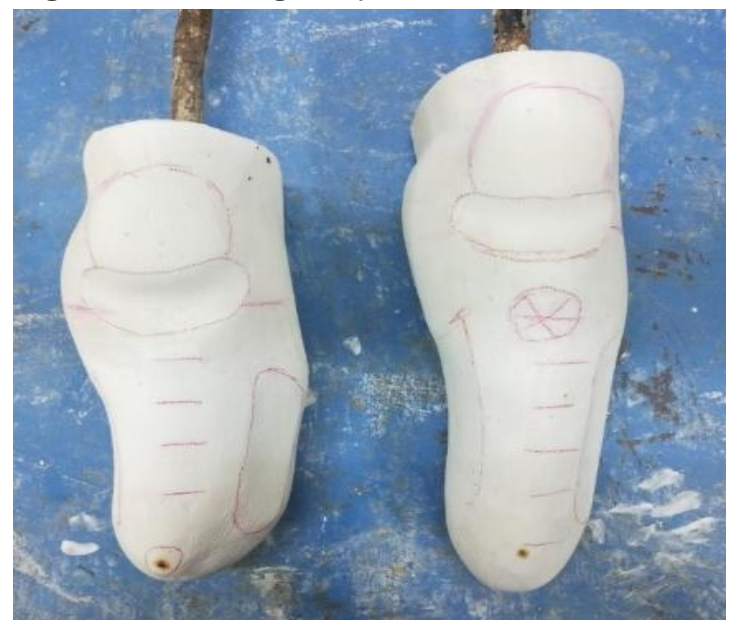

Fig.3 Modified mold with markings 


\section{SOCKET TRIAL:}

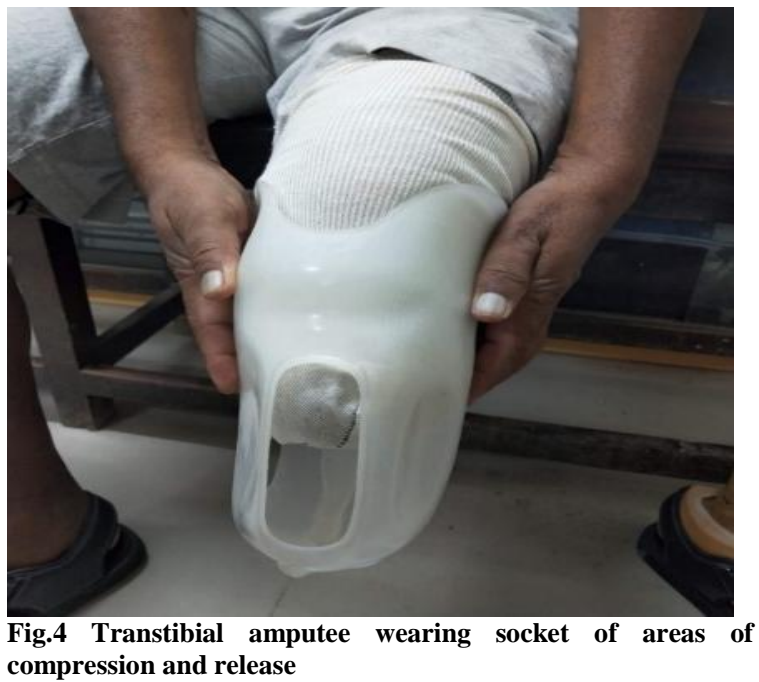

\section{RESULTS AND DISCUSSION}

The present socket is well suitable for transtibial patient in weight bearing position. It fits well to the contour of the adult patient. The socket was adjusted manually during rectification phase providing respective pressure in areas required.

Trial is limited to only one patient due to less availability of time. The socket cannot be used in case of diabetic patient as it provides more locks in the bony prominences and does not provides a uniform pressure using liners. This is one of the major and first trail conducted in case of a person using a preliminary socket with minimum rectification.

From the above study it is observed that, fine adjustment and development of new sockets are required. As a result, it will be helpful to achieve the base in healthy conditions. Further, this invention will be necessary for the better outcome of the development.

\section{Limitations of the Study}

Small sample sizes with bounded time were a major limitation of this study. Only non-diabetic patients can be included in this study which may limit the results for all populations.

\section{FUTURE SCOPE}

In future, the study can be carried out in large samples.

\section{CONCLUSIONS}

Human, the most intelligent and fine-tuned machine always have an eye for developing devices that will reduce the human efforts and the productivity process. In case of transtibial amputee, the prosthetist faced a lot of challenges during socket fitment, which in turn also provides lots of discomfort for amputee. In order to make this process streamlined and convenient for both the amputee and rehab professionals, this socket was designed to reduce the difficulties and facilitate accurate socket fitment by single individual.

The developed socket had a great effect on gait pattern of transtibial amputee. In these cases, the alignment of socket i.e. prosthetic alignment was the most significant approach. The socket had a positive impact in the field of prosthetics. Moreover, it was made up of indigenous materials and is simple in design concept. This socket provides adjustment for pressure, anterior, posterior, medial and lateral of the stump. It also creates surface for the placement of bony prominences. As it is a complex casting procedure, proper care should be taken to fabricate the casting of socket with minimal error.

Further, innovative inventions will be required to refine more products and extensive study has to be carried out on the existing mode.

\section{Acknowledgement: None}

\section{Conflict of Interest: None}

\section{Source of Funding: None}

\section{REFERENCES}

1. Nielsen CC. A survey of amputees: functional level and life satisfaction, information needs, and the prosthetists role. J Prosthet Orthot 1990;3:125- 129.

2. Laing S, Lee P, Goh J. Engineering a TransTibial Prosthetic Socket for the Lower Limb 
Prachi Prava Pattnaik et.al. Design \& development of a trans tibial socket stabilized by alternating areas of tissue compression and release - a case study.

Amputee. Annals of the Academy of Medicine, Singapore, May 2011.

3. Dillingham TR, Pezzin LE, MacKenzie EJ, Burgess AR. Use and satisfaction with prosthetic devices among persons with trauma-related amputations: a long-term outcome study. Am $J$ Phys Med Rehabil 2001;80:563-571.

4. Legro MW, Reiber G, del Aguila M, et al. Issues of importance reported by persons with lower limb amputations and prostheses. J Rehabil Res Dev 1999;36(3): 155-163.

5. Klute GK, Kantor C, Darrouzet C, et al. Lower-limb amputee needs assessment using multistake holder focus-group approach. J Rehabil Res Dev 2009;46(3): 293-304.
6. Kristinsson O. Pressurised casting instruments. Proceedings of the 7th World Congress, International Society of Prosthetics and Orthotics. Chicago (IL); 2002.

7. Anamika Sahu, Psychological effects of amputation: A review of studies from India, industrial psychiatry journal 2016;25(1):410.

How to cite this article: Pattnaik PP, Jonathan T. Design \& development of a trans tibial socket stabilized by alternating areas of tissue compression and release - a case study. Int $J$ Health Sci Res. 2021; 11(7): 317-321. DOI: https://doi.org/10.52403/ijhsr.20210744 